\title{
A música na era de suas tecnologias de reprodução ${ }^{1}$
}

\author{
Simone Pereira de Sá ${ }^{2}$ \\ UFF \\ sibonei@gbl.com.br
}

\begin{abstract}
Resumo: $O$ trabalho tem por objetivo compreender as reconfigurações musicais da cibercultura dentro de uma história cultural das tecnologias ligadas à reprodutibilidade sonora na modernidade, a fim de evitar uma aproximação determinística e linear do problema. Na primeira parte, o texto aborda o circuito de produção-circulação-consumo de música massiva a partir de três eixos: 1) das tecnologias eletro-magnéticas e de gravação; 2) das tecnologias aplicadas ao desenvolvimento de instrumentos musicais; 3) dos artefatos de audição e armazenamento da música. A seguir, na segunda parte, são encaminhadas algumas questões sobre o cenário presente, propondo-se abordagens do fenômeno musical na cibercultura que levem em conta as apropriações culturais e as mediações de nova ordem.
\end{abstract}

Palavras-chave: música massiva - tecnologias sonoras - cibercultura.

Abstract: The paper aims to comprehend the musical reconfiguration of cyberculture articulated to aspects of a cultural history of sound technologies in the modernity, in order to avoid a deterministic and linear aproach to this problem. In the first section, the analyses focus on the productioncirculation-consumption circuit of the massive music, organized in three axis: 1) electro-magnetics and recording technologies 2) musicals instruments 3) auditions and storage artefacts. In the second section, the analyses is on samples of cyberculture musical practices, when we enphazise the need to consider the new modes of mediations.

Key words: mass music - sound technologies - cyberculture.

Résumé: L'article propose comprendre la reconfiguration musicale de la ciberculture dans une histoire culturelle des technologies articulées à la

\footnotetext{
${ }^{1}$ Trabalho apresentado ao GT de Tecnologias da Comunicação, para a XV COMPOS, UNESP, Bauru, 2006

2 Professora do PPGCOM/UFF; doutora; coordenadora do Laboratório de Cultura Urbana, Lazer e Tecnologias (LabCult-UFF)
} 
reproductibilité sonore dans la modernité, afin de éviter une approche déterministe et linéaire du problème. La première partie aborde le circuit de la production-circulation-consommation de musique massive à partir de trois axes: 1) technologies électromagnétiques et de enregistrement; 2) technologies appliquées au développement des instruments musicaux; 3) des artefacts d'audition et emmagasinement de musique. En suite, la deuxième partie analyse des questions sur le scénario atuel, et propose des abordages de phénomène musical dans la ciberculture qui mettent en relief les appropriations culturelles et les médiations de la nouvelle ordre.

Resumen: Este artículo se propone comprender las reconfiguraciones musicales de la cibercultura, dentro de una historia cultural de las tecnologías vinculadas a la reproductibilidad sonora en la modernidad, con el fin de evitar una aproximación determinista y lineal del problema. En la primera parte, el texto aborda el circuito de producción-circulación-consumo de música masiva a partir de tres ejes: 1) las tecnologías electromagnéticas y de grabación; 2) las tecnologías aplicadas al desarrollo de instrumentos musicales; 3) los artefactos de audición y de almacenamiento de música. En la segunda parte del texto se presentan algunas cuestiones sobre el escenario actual, y se proponen abordajes del fenómeno musical en la cibercultura considerando las apropiaciones culturales y las mediaciones de nuevo orden. 


\section{Apresentação}

Uma das principais questões suscitadas pelo universo de práticas ligadas à comunicação mediada por computador diz respeito à reconfiguração dos papéis de emissor e receptor a partir da noções de hipertexto e interatividade.

Sob a forte influência de Pierre Lévy, difundiu-se entre nós o argumento de que a Internet constitui-se como um novo ambiente, que tem dentre as suas principais características a possibilidade de reversão dos jogos de poder ligados à centralização das mídias massivas.A premissa, como sabido, é a de que a comunicação um-todos, típica do modelo implantado pela cultura de massa, deu lugar ao modelo todos-todos que resulta da conexão generalizada em rede, onde emissores e receptores, ou no exemplo da produção artística, artista e público se confundem ou alternam papéis.

No caso da música, que é o foco de meu interesse neste artigo ${ }^{3}$, o argumento tem sido utilizado para compreender as potencialidades do computador e da Internet na consolidação de um novo modelo de escuta e consumo musical cuja ênfase é na relação direta entre produtores e consumidores, não mais subdita aos ditames da indústria fonográfica.

De fato, tocadores do formato $\mathrm{MP}_{3}$, trocas de arquivos musicais a partir do advento de ferramentas par-a-par, download de ringtones para celulares, bandas que dispensam gravadoras e divulgam seu trabalho na rede, podcasting; além do incontável número de sites, blogs, listas e comunidades no orkut criadas por músicos, críticos e aficccionados apontam, em conjunto, para a efervescência das práticas musicais na cibercultura.

Entretanto, para discutir efetivamente o teor destas reconfigurações, creio que um primeiro passo é o de inseri-las dentro de uma história cultural da audição, que seja ao mesmo tempo uma história das tecnologias ligadas à escuta, reprodução e consumo do som na modernidade, no contexto da música massiva. ${ }^{4}$

\footnotetext{
3 Fruto da pesquisa: O Local na (ciber) cultura: tecnologia, estética e identidades na música eletrônica do Brasil,coordenada pela autora no PPGCOM/UFF, dentro da linha de tecnologias e financiado pelo CNPQ.

4 Remeto o leitor à definição de Janotti Jr.(2005) Para o autor, a música massiva supõe as expressões "que se valeram do aparato mediático contemporâneo, ou seja técnicas de
} 
Creio que este esforço justifica-se por diversas razões. Primeiramente, porque, inexplicavelmente, a compreensão da música na era das tecnologias de reprodução tem merecido menos atenção por parte de pesquisadores de comunicação brasileiros do que o campo da imagem ou da imprensa. Seja por uma certa naturalização do som como objeto do conhecimento num país tido como intuitivamente musical; seja por predominar nos estudos brasileiros uma vertente memorialista ou tradicionalista ligada à defesa da música popular, a problematização do som como importante vertente da cultura de massa e a história de sua articulação com artefatos tecnológicos não tem recebido o tratamento merecido entre nós. O que resulta em informações dispersas encontradas somente em bibliografia não traduzida, sem falar de uma certa rejeição romântica a esta associação, como se a tecnologia fosse contrária à criação musical

Além disto, compreender esta história ajuda-nos a refletir com mais refinamento sobre o presente, ressaltando a não linearidade das apropriações tecnológicas e livrando-nos do caminho determinista e profético de alguns trabalhos que alardeiam o fim das escutas tradicionais ligados ao disco, à canção ou a certos aparelhos de reprodutibilidade. Ao mesmo tempo, ela nos ajuda a compreender efetivamente o que se remedia na cibercultura - ou seja como as novas tecnologias de audição se imbricam com as anteriores, e quais os pontos de ruptura.

Finalmente, creio que se trata de uma história saborosa, com lances surpreendentes, que merece ser compartilhada por estudiosos das tecnologias da comunicação.

Esse texto representa, portanto, um esforço nesta direção. Inspirada por estudiosos oriundos do campo dos estudos culturais e afins, proponho na primeira parte uma pequena e incompleta genealogia das formas de produção e consumo musical na modernidade, inserindo os fenômenos ligados à cibercultura dentro de uma história mais longa. Feito o mapa, encaminho a seguir algumas questões sobre o cenário presente, reivindicando análises posteriores que levem em conta as apropriações culturais e as mediações de nova ordem.

produção, armazenamento e circulação tanto em suas condições de produção bem como em suas condições de consumo." 


\section{1) Tecnologias e artefatos para a comodificação musical}

Qualquer discussão sobre o papel da tecnologia na música popular deve partir de uma simples premissa: a de que, sem as tecnologias eletrônicas, a música gravada do século XX é simplesmente impensável."A música pop, tal com nós a conhecemos, foi formatada pelo problema de fazer da música uma comoditie e os desafios de adaptar práticas de ganhar dinheiro a tecnologias em transformação."(Frith;2001)

O que o autor chama de "transformar a música em comoditie" é o processo que ocorre no último século e meio, através do qual algo, por um lado etéreo, e por outro cotidiano e compartilhado por uma coletividade, tal como a música, deve ser transformada em mercadoria, submetida às relações de compra e venda. E cujo primeiro passo é a separação da composição e da performance a partir da notação musical e da impressão de partituras em fins do século XIX, em paralelo ao desenvolvimento da indústria de pianos, pianolas e afins.(Thebergé; 1997)

Este primeiro marco do processo de comodificação produz três conseqüências que merecem atenção.

A primeira delas é o estabelecimento de fronteiras entre a música comercial - que é a música cifrada, que pode ser transposta para partituras: e a música nãocomercial, de tradição oral, chamada de folclórica, cujo processo de composição, arranjo e transmissão dificultava sua transposição para o universo das cifras.

A segunda é o estabelecimento de uma nova hierarquia de músicos, onde de um lado surge a figura do virtuoso musical, o gênio romântico, de outro os músicos amadores, que compram partituras e pianos para consumo doméstico, no âmbito das atividades de lazer, sem maiores pretensões artísticas. Este processo supõe, por sua vez, o surgimento de dois novos mercados: o dos consumidores de música "ao vivo", que substituem os patronos musicais pagando por concertos de músicos profissionais, que sabem tocar; e o da classe média que paga para aprender música no ambiente do lar. 
A terceira é a série de medidas de regulamentação dos direitos autorais, que vão ser tomadas contra o roubo e a pirataria e que consolidam as categorias de editor, de compositor e de copyright. 5

Se este primeiro marco é importante por sinalizar o momento em que a música torna-se pret-a-porter, podendo ser apropriada, reproduzida e consumida para além do local original de sua criação, por indivíduos que não sabem tocar um instrumento; a consolidação do mercado de música massiva remete-se a um cenário mais complexo, que proponho analisar como articulado em três pólos a partir das sugestões de Thebergé.(2001)

No terreno da produção, temos os eixos: 1) das tecnologias eletromagnéticas e de gravação e 2) das tecnologias aplicadas ao desenvolvimento de instrumentos musicais; e no da reprodução, o eixo 3 , dos artefatos de reprodutibilidade e armazenamento musical.

\section{1) Tecnologias eletro-magnéticas}

No primeiro eixo, cabe destacar primeiramente a importância do trio microfone, amplificação elétrica e alto-falantes, centrais na experiência estética de escuta moderna.$^{6}$. Conforme nos lembra o autor, este trio foi de certa forma naturalizado dentro do debate em questão; e seus efeitos, tornados transparentes no discurso da alta fidelidade e da reprodução que acompanham o desenvolvimento da música gravada. Entretanto, seu impacto na história da música massiva é ao mesmo tempo sutil e profundo. É o microfone que vai permitir uma nova forma de cantar num estilo mais coloquial e sussurrado (o estilo dos crooners tais como Bing Crosby, ou no caso brasileiro, Francisco Alves e Carmen Miranda); e sua associação à amplificação e aos alto-falantes permite que vozes até então vistas como pequenas

\footnotetext{
5 Conforme Shuker (1999; 98), a primeira lei de defesa dos direitos autorais na música foi decretada nos EUA em 1909, seguindo-se legislação semelhante na Inglaterra, em 1911. ${ }^{6}$ Vale observar que nenhum dos três elementos foi desenvolvido primeiramente para a indústria fonográfica. $\mathrm{O}$ microfone desenvolveu-se primeiramente para a telefonia e sistemas de rádio broadcasting; a amplificação origina-se do Audion Tube de Lee DeForest, em 1904; e os alto-falantes são introduzidos no rádio e em sistemas de comunicações púbicas em 1920, desenvolvendo-se a partir do interesse dos cinemas. E lembrando o importante argumento de Sterne (2003), eles são fruto do intenso interesse científico pela audição em fins do século XIX.
} 
possam ser registradas e apreciadas com qualidade. Da mesma forma, o desenvolvimento de estilos como o jazz - onde instrumentos como o baixo devem ser ouvidos com nitidez e sutileza; ou posteriormente do rock and roll e sua estética da distorção de guitarras amplificadas são altamente dependentes destas inovações.

Além disto, cada tipo de microfone tem suas próprias características, revelando em detalhes íntimos as nuances da performance do músico ou cantor, colorindo ou aquecendo uma voz de maneiras diferentes, sofisticando o prazer da escuta musical e supondo o desenvolvimento de técnicas de gravação específicas para captação de sons.

Ao trio mencionado, devemos associar o desenvolvimento das técnicas de gravação. Primeiramente a gravação elétrica, que surge como uma inovação em meados dos anos 20 e associa-se ao formato de disco de ebonite de 10 polegadas, de 78 r.p.m, que registrava cerca de quatro minutos de gravação em cada um dos lados.Mas principalmente, o avanço propiciado pela gravação magnética, surgida a partir do pós-guerra, que flexibiliza, facilita e barateia enormemente as gravações em estúdio e ao mesmo tempo, permite uma maior qualidade.

Aqui, mais uma vez, cabe enfatizar o fato de que não se trata simplesmente de uma nova técnica de reprodução sonora, mas sim de um processo que reconfigura as noções de performance e gravação em estúdio, permitindo cortes, edições e experimentações diversas.

A utilização das gravações magnéticas não se restringe, porém, ao universo da produção de discos. Para compositores, a nova técnica torna-se de especial utilidade, uma vez que qualquer boa idéia musical pode ser registrada imediatamente. Além disto, a partir do pós-guerra, músicos ansiosos por aprenderem e copiarem novos estilos baseados no improviso - tais como o jazz, o rockabily e o rhythm and blues - viram na gravação a melhor forma de reproduzir o que escutavam nos night-clubs.Finalmente, cabe registrar a sua utilização pela vanguarda erudita, em nomes tais como Schaeffer, Pierre Henry e Stockhousen, cujas experimentações irrigam posteriormente o terreno do pop.

Durante os anos 60, as possibilidades da gravação magnética são ainda mais exploradas, a partir da sua associação com o sistema multicanais. O desenvolvimento 
de um sistema onde os instrumentos e vozes podem ser gravadas em canais diferentes, separadamente, abre um enorme campo de possibilidades de experimentações, no qual os diversos materiais pré-gravados podem ser retrabalhados de acordo com os interesses de consumo variados.

Neste momento, fica claro que a gravação em estúdio não é somente o registro de uma sonoridade anterior e original (a da performance ao vivo); mas sim um processo de criação musical per se, com sua própria estética, valores e referências. Processo que, ao mesmo tempo, ressignifica o papel do produtor - que ganha destaque e trabalha em colaboração estreita com o músico, que também adquire conhecimentos técnicos para dialogar e intervir. ${ }^{7}$

A partir desta compreensão, torna-se comum, desde os anos 70, que grandes músicos invistam em seus próprios estúdios, a fim de que possam experimentar livremente, longe da pressão de pagamento de horas dos estúdios comerciais.Ao mesmo tempo, o domínio das tecnologias, rotinas e práticas de gravação torna-se parte das exigências do "tornar-se um músico pop", tanto quanto saber afinar um instrumento.

Entretanto, esta prática só pode ser compreendida em todo o seu sentido cultural quando lembramos que ela se desenvolve associada a um novo suporte de registro, o long play - disco de vinil de 12 polegadas e 33 1/3 rpm, com maior capacidade de armazenamento, lançado pela Columbia em 1948.(Magoun; 2002)

Numa história já abordada entre nós por Marchi (2004) e Janotti (2005), o fato a sublinhar é o de que o LP define ao mesmo tempo uma nova concepção musical - a do álbum como um produto "fechado", com canções interligadas, com duração de cerca de quarenta minutos, com lado A e lado B; além do desenvolvimento de uma estética ligada às capas, um tipo de texto que apresenta o compositor, etc.

A partir de seu desenvolvimento, no início dos anos 50, o LP tornou-se o principal formato para a música clássica e os estilos orientados para o público adulto - inclusive o rock and roll com pretensões de "amadurecimento" nos ano 60;

\footnotetext{
7 Teo Macero (in Shapiro; 2000; 54), produtor de Miles Davis, faz interessante revelações sobre a parceria dos dois em diversos discos. Muitas vezes Davis não aparecia no estúdio, enviando fitas cassete que iam sendo trabalhadas por Macero.
} 
enquanto o disco de $45 \mathrm{rpm}$ associa-se aos singles destinados às emissoras de rádio, jukeboxes e vendas a varejo.

Antes dele, como vimos, outros suportes já haviam dado sua contribuição para formatar a música como produto midiático. Pois, conforme enfatiza Janotti (2005) a partir de Tatit, a formatação da canção popular massiva como música com cerca de três minutos de duração é devedora do disco de $78 \mathrm{rpm}$ desenvolvido na década de 20. Para os músicos e produtores, porém, o LP confirma a consolidação da noção de autoria e de obra de arte; e para os fãs, trata-se do ápice de uma história de culto, na qual, a noção de uma enciclopédia musical ou de uma coleção ganha todo o seu sentido cultural, conforme enfatiza Marchi no trabalho mencionado.

Voltando às gravações magnéticas, cabe ainda demarcar o momento de introdução das fitas cassete no mercado, em 1963. De um meio com baixa qualidade de reprodução, ela torna-se, em uma década, um suporte bom o suficiente para reproduções de qualidade (a partir do sistema dolby de gravação) e barata o suficiente para compensar eventuais deficiências na qualidade de reprodução. Para músicos, ela torna-se o suporte preferido para a apresentação do trabalho junto às gravadoras, rádios ou mesmo para venderem junto aos fâs.E, assim, a fita demo que contém gravações inéditas, pode ser duplicada em várias cópias de forma barata e imediata - atribui um significado cultural único às fitas cassete.

Também nos anos 70, a sua associação ao transistor permite que os baratos gravadores sejam incorporados aos aparelhos estereofônicos de alta fidelidade. O desenvolvimento de poderosos aparelhos estéreos portáteis (as boom boxes ou ghetto blasters) criou uma nova forma de identificação entre os afro-descendentes novaiorquinos e contribuiu de maneira definitiva para a difusão e expansão do rap em fins dos anos 70. No momento em que esta era uma música anti-comercial, emergente dos guetos, feita e tocada para teenagers mais interessados na espontaneidade das festas que faziam do que na gravação de discos, o cassete foi o suporte que registrou e levou adiante a primeira expressão deste gênero. (Millard;2002)

E, nos paises em desenvolvimento tais como a Índia, além do continente africano, a fita cassete tornou-se o principal veículo para consumo de música, superando em finais dos 80 a venda de outros suportes por mais de três vezes; e 
possibilitando a circulação de uma produção local que irrigou a cultura pop durante as décadas de 80 e 90 sob o rótulo de world music.

A contínua democratização do acesso dos músicos às tecnologias de gravação consolida-se com a introdução do protocolo de hardware/software MIDI (Music Instrument Digital Interface) em 1983, que possibilita a associação de sintetizadores digitais, samplers, baterias eletrônicas e computadores, trabalhando conectados em rede, consolidando a noção de home studio - tema ao qual retorno adiante.

\section{2) Instrumentos musicais}

O segundo eixo merecedor de atenção nesta discussão é o das tecnologias aplicadas ao desenvolvimento de instrumentos musicais. Mencionei anteriormente o pioneirismo da indústria de pianos. Entretanto, no universo da música pop, cabe destacar a importância central da guitarra elétrica; do conjunto de instrumentos percussivos; e do toca-discos, que ganhou status de instrumento a partir da cultura da música eletrônica.

A eletrificação da guitarra me interessa por tratar-se de um bom exemplo de como a apropriação tecnológica escolhe caminhos pouco usuais para se concretizar.(MacSwain;2002). O contexto onde primeiramente a eletrificação desenvolveu-se foi o das bandas de jazz, que tocavam em barulhentos night-clubs e dance halls nos EUA dos anos 20; e contavam elas mesmas com um conjunto de músicos numerosos e também ruidosos, tornando a amplificação sonora uma necessidade. Realizada a partir das tecnologias disponíveis na época, a amplificação provocou como efeito colateral o surgimento de sons indesejados, o mais reconhecido sendo o feed-back, ou resssonância de uma nota por mais tempo do que o desejado. Numa bem sucedida colaboração entre músicos e técnicos de som, sob a coordenação de Leo Fender, o corpo da guitarra foi então redesenhado em direção a um formato sólido, abolindo-se a parte interna oca, a fim de eliminar os ruídos e maximizar o volume. Surge no mercado a guitarra Fender Esquire, apresentada ao público em 1950.

Entretanto, numa interessante reviravolta, os anos 50 assistem a um processo de reconceitualização do instrumento onde justamente o feed-back e outras 
sonoridades até então vistas como barulhos inoportunos passam a ser valorizadas.Assim, o guitar man do rock - cujo exemplo emblemático pode ser Jimi Hendrix tocando o hino americano distorcido e ruidoso na sua Stratocaster em Woodstock- constrói o seu estilo em cima destes efeitos. São eles que formatam de forma definitiva a estética do gênero, deixando claro que o guitarrista toca "com o instrumento e com a eletricidade", numa história que supõe escolhas e divergências também em torno de outros recursos tais como os pedais e seus efeitos de reverberação, eco, delay, etc

Tão importante quanto, mas talvez menos óbvia aos leigos são as alterações que o conjunto percussivo ao qual nos referimos genericamente como bateria sofre a partir de manipulação eletrônica e dos desenvolvimentos das técnicas de gravação.A separação dos instrumentos percussivos em canais diferentes, permitido pela gravação multicanal, é um primeiro passo, que tem como efeito a alteração da percepção espacial do ouvinte de diversas maneiras. Entretanto, é a introdução da bateria eletrônica - artefato que contém padrões rítmicos e uma diversidade de sons para reprodução mecânica - que vai ser fundamental na definição da estética de diversos estilos do pop ${ }^{8}$.

Junto com o trio formado por samplers, sintetizadores e sequenciadores 9 , estas ferramentas alteram a estrutura e a lógica das práticas musicais - enfatizando ainda mais o aspecto de produção em detrimento do domínio de um instrumento - e os conceitos sobre o que é música. Ao mesmo tempo, colocam a música numa nova relação com práticas de consumo, uma vez que o próprio músico é, cada vez mais, um consumidor de sons pré-gravados.

O terceiro exemplo a ser destacado é o da cultura da música eletrônica. Numa história que remonta novamente ao rap, quando imigrantes jamaicanos do Bronx começam a tocar discos em suas festas, editando-os ao vivo a partir de dois toca-discos e desenvolvendo técnicas de intervenção no vinil, tais como o scratch - o

\footnotetext{
8 . 8 É o caso da Roland TR-808, bateria que se torna a preferida de produtores de rap e house. 9 Respectivamente, o sampler é o aparelho que permite a gravação e reprodução de timbres extraídos de qualquer fonte; o seqüenciador é um processador de texto musical, que permite ao músico a manipulação de parâmetros sonoros a partir de códigos digitais; e o sintetizador possibilita a programação e controle de variáveis tais como timbre, altura, intensidade e duração dos sons.
} 
fato a enfatizar é o da reconfiguração do aparelho, que se torna um instrumento musical a ser manipulado para a extração de sonoridades inusitadas, com consequências para as noções de obra de arte, de disco como produto fechado e de autoria (tema que abordei em trabalho para este GT no ano de 2003.)

\section{3) Formatos/aparelhos de consumo}

Finalmente, o terceiro eixo nos remete ao conjunto de tecnologias ligadas ao consumo musical e que implica em considerar o desenvolvimento de formatos e suportes ${ }^{10}$ para a veiculação de música gravada tanto quanto os aparelhos de reprodução.

Neste eixo, cabe considerar por um lado os suportes que, desde o cilindro do fonógrafo de Edison e discos de goma-laca do gramofone desenvolvido por Berliner, passando pelos diversos tipos de discos e chegando ao $\mathrm{CD}^{11}$ exploram a noção de reprodutibilidade.

Concomitantemente, desenvolvem-se os aparelhos de reprodução sonora: desde os pianos e pianolas para serem tocadas com partituras nos saraus que reuniam as famílias na virada do século XIX; destes aos gramofones e grandes rádios adquiridos para serem ouvidos também na sala residencial, na primeira metade do século $\mathrm{XX}$; aos rádios e toca-discos portáteis que vão ocupando os diferentes cômodos a partir do pós-guerra e permitem aos adolescentes uma escuta musical diferenciada dos pais, em seus próprios quartos, num processo de capilarização, individualização e customização crescente da escuta.

Processo que acaba rompendo as fronteiras do lar e acompanha o indivíduo em seu percurso urbano. Seja na sucessão de artefatos miniaturizados tais como o walkman e afins; seja nos sistemas sound-blasters que demarcam o território

\footnotetext{
${ }^{10}$ Dantas(2005) propõe uma distinção entre suporte como a base física; e formato, que seria a forma cultural de apropriação. Sem espaço para aprofundar a discussão, registro que, do meu ponto de vista, estas duas categorias estão intrinsecamente ligadas.

${ }^{11}$ Lançado em 1983, o compact disc é um disco de 4,5 polegadas, com aparência de alumínio, gravado de um só lado, com tecnologias digitais. Sem introduzir grandes modificações no formato cultural estabelecido pelo disco de vinil, a não ser a abolição dos lados A e B, ele torna-se o principal meio de lançamentos musicais, substituindo paulatinamente seu antecessor no mercado global ao mesmo tempo que confirmando a noção de álbum e canção como formas dominantes da escuta massiva.
} 
dividido em guetos da cultura do rap, possibilitando ao indivíduo ou ao sub-grupo a construção de uma narrativa musical que desafia ou dialoga com outros ruídos urbano, apontando para passos de uma apropriação dos artefatos técnicos que merecem uma análise caso a caso, onde entra também a linhagem dos karaokês, videokês, gravadores de $\mathrm{CD}$, etc ${ }^{12}$

\section{4) Tendências da comodificação}

Numa visada geral que interligue os três eixos aqui abordados, podemos agora perceber que a comodificação musical está ligada a um processo mais amplo que Sterne chama de instauração do "regime de audição" da modernidade, codificando uma "atitude burguesa" em relação ao som cujos principais elementos alinho a seguir.

Primeiramente, estas técnicas de ouvir articulam-se à razão científica e à racionalidade. Na invenção dos mais diversos artefatos para produção e reprodução, uma mesma operação de abstração, quantificação, medição e registro do som são fundamentais, apontando para a operação da construção sonora como objeto do conhecimento. Paralelamente, a audição é também isolada dos outros sentidos - a fim de ser estendida, ampliada, modificada e codificada.Concomitantemente, esta construção toma o som como problema, construindo as noções de interior e exterior acústico.

Além disto, elas reconstróem o espaço acústico como um espaço privado, isolado, pertencente a um indivíduo, onde busca-se eliminar os ruídos vindo do exterior. E apontam para uma conquista do universo burguês: o direito ao silêncio para que a apreciação sonora individual possa ser atingida mesmo em espaços públicos ( tais como as salas de concerto, a cabine de telefone ou o isolamento possibilitado pelos headfones).

Como parte deste processo, estes aparatos criam as bases de uma nova estética sonora que valoriza os detalhes sônicos: a distinção de ruídos, variações de timbres ou ritmos, pausas e outras sutilezas da expressão sonora vão ser valorizadas

\footnotetext{
12 Para interessante análise deste processo relacionado ao walkman, ver Bull; 2001. 
na apreciação musical, através da noção de high fidelity dos aparelhos de reprodução musical.

Para tanto, a educação cognitiva para lidar com estes artefatos é fundamental.Por um lado, esta educação implica em aprender a ouvir certos sons e identificá-los como semelhantes à fonte original - processo que nada tem de natural (haja visto o estranhamento que sentimos ao ouvir nossa própria voz gravada). Por outro lado, implica em aprender a lidar com as possibilidades de customização através de controles do volume, da equalização de graves e agudos e assim por diante.

Enfim, o consumo burguês de música remete para um universo de sons crescentemente pré-fabricados, mesmo entre músicos profissionais, tensionando o modelo do músico como o virtuoso que sabe tocar um instrumento em prol do músico/produtor.

Além deste elenco de questões, cabe ainda ressaltar outros três desdobramentos importantes da discussão.

O primeiro é o de que a comodificação aponta para uma tensão entre o consumo público e privado, uma vez que por uma lado, a reprodutibilidade traz para o âmbito doméstico o som antes só ouvido nas salas de concerto. Pianos, rádios, gramofones e que tais têm em comum serem janelas para o mundo da música, disputando e competindo com as formas públicas e esta é a grande sedução destes aparatos de mediação. Entretanto, como é sabido, o consumo público de música não desapareceu. Ele reconfigurou-se a partir dos aparatos técnicos - microfones, amplificação, sistemas de som cada vez mais potentes, grandes sistemas de telas para visibilidade nos shows em espaços gigantescos - alcançando proporções jamais imaginadas.Aqui, o grande desafio é o da reprodução do som tal como ele foi gravado, uma vez que o público muitas vezes conhece a música a partir da gravação (numa lógica que inverte a relação entre original e cópia)

Uma segunda tensão se dá entre os pólos do consumo de objetos "fechados" - tais como discos, CDs, DVDs, etc.; e as formas de apropriação customizada tais como gravações de fitas e vídeos cassete - para serem ouvidos nos mais diferentes suportes - além de karaokês e videokês, somando-se às intervenções na gravação original, tal como se tornou prática, por exemplo, na cultura da música eletrônica. 
Finalmente, cabe destacar o papel das comunidades de gosto tais como as cenas e as subculturas e das regras de gênero musical ${ }^{13}$ mediando a relação da tecnologia com o consumo a partir do estabelecimento de valores e hierarquias, uma vez que a avaliação e a identificação, presentes na pergunta "Com que se parece este som?” ou do ponto de vista da indústria, "quem vai consumir esta música?"permanecem como nortes do consumo musical.(Janotti Jr; 2003). Assim, certas inovações tecnológicas são impensáveis dentro de certos gêneros e muito apreciadas por outros; e toda a apropriação cultural deve ser analisada dentro desta moldura.

De que forma a cibercultura reconfigura estas premissas?

\section{2) Cibercultura e consumo musical}

A discussão sobre a produção-circulação-consumo na cibercultura implica na consideração de um universo complexo de práticas que merecem análises pontuais, caso a caso. Simplificando o quadro, entretanto, podemos pensar novamente em três eixos que orientem análises futuras $\mathrm{O}$ primeiro é das práticas de produção possibilitadas pelo desenvolvimento de softwares e especialmente do protocolo MIDI, consolidando a noção do home studio como tradução de um processo de produção crescentemente autônomo e independente das grandes gravadoras; o segundo é o pólo do consumo, onde destaca-se o fenômeno de napsterização da música - ou seja, sua apropriação a partir do desenvolvimento do formato $\mathrm{MP}_{3}$, responsável pela compressão de dados, associado a protocolos de troca par-a-par; que se completam a partir do desenvolvimento de aparelhos reprodutores tais como o I-pod;. e o terceiro é o do universo da circulação ou da distribuição, constituído pelos sites, listas, revistas, blogs e podcasts dedicados à música. Eixos interligados, que aqui serão pensados como transversalmente atravessados por três conjuntos de problemas que já discuti anteriormente (Sá; 2005)

Um primeiro ponto diz respeito à desmaterialização da música a partir de sua digitalização, transformando-se em bits que podem ser acessados, lidos e traduzidos em suportes variáveis, virtualizando-se. E pode ainda ser reprocessada,

\footnotetext{
13 Para a discussão sobre gênero, ver Frith (1996) e Janotti (2003). Este ressalta ser necessário levar em conta os aspectos mercadológicos, semióticos (os sentidos e expressões comunicacionais do texto musical) e as regras técnicas e formais para uma discussão desta noção no universo da música massiva.
} 
sampleada e reconectada com outros sons através de softwares específicos, num processo aberto e potencialmente infindável. Processo que se completa a partir do desenvolvimento de suportes reprodutores tais como celulares, tocadores portáteis de MP3, podcasting - que, por sua vez, também remetem a um universo de utilizações flexíveis e de convergências.

Desta forma, a noção de produtos fechados tais como o disco e junto com ele o aparelho para reprodução sonora estão sendo problematizados, explicando parte dos problemas da indústria fonográfica.

Em segundo lugar, caberia destacar o lugar central da noção de consumo participativo, que se refere às formas de entretenimento que convidam o usuário a participarem ativamente do processo. (Thebergé; 1997; 252/253)

Esta noção - comercialmente traduzida como interatividade - pode ser pensada como o novo fetiche da escuta musical, que se sobrepõe ao fetiche anterior da high fidelity. Ou seja: se no primeiro momento da história da reprodução sonora, o desafio das máquinas de audição era o de uma certa definição sonora que fosse convincentemente comparável à fonte original; a demanda para nossos artefatos de escuta é o de permitirem todo o tipo de intervenção do usuário no sentido não só de customizar suas escolhas - acondicionando suas músicas favoritas no celular; escolhendo o ringtone; mas de produzir o seu próprio acervo sonoro através de bricolagens sonoras que podem combinar de maneira inusitada produções pessoais e sons pré-existentes.

Finalmente, como terceiro ponto ressalto a noção de desintermediação musical. Conseqüência direta das novas formas de produção, tais como o home studio; e das possibilidades de circulação da música na rede, tais como sites, listas, blogs e podcasts; torna-se cada dia mais comum a história de bandas ou artistas que divulgam seu trabalho sem a intermediação das gravadoras; ou de aficcionados que têm acesso direto ao trabalho dos músicos preferidos, discutindo, criticando e/ou demandando gravações de forma direta, driblando-se assim a centralização e as estratégias de marketing das gravadoras. 
Sem dúvida, tratam-se aqui de reconfigurações importantes que problematizam as práticas do circuito de produção-circulação-consumo anterior e obrigam todo o universo das práticas musicais a se repensar.

Entretanto, alguns contra-exemplos, pinçados aleatoriamente do universo em questão, demonstram a complexidade do cenário.O primeiro é o das bandas que divulgam seu trabalho através da Internet; para a seguir assinarem contrato com uma gravadora. Esta prática, que tem se tornado a regra, aponta para um passo atrás no que estava sendo tomado como o processo de desintermediação musical. O segundo é o fato de que fãs de bandas aproveitam as possibilidades de troca gratuita de música baixando álbuns inteiros de seus ídolos para serem ouvidos nos I-pods e afins, conforme ressalta Dantas (2005). Neste caso, a conexão com um universo de escolhas musicais é utilizado para confirmar gostos previamente construídos a partir das subculturas e dos gêneros musicais. E a miniaturização, apropriação individual, mobilidade e capacidade de armazenamento de seus players são os maiores atrativos, em linha direta de continuidade com os walkmans da geração anterior. Finalmente, o terceiro exemplo advém da música eletrônica e diz respeito à rejeição de alguns Djs à prática do download em prol do garimpo de discos de vinil em sebos, remetendo a uma discussão sobre valores, autoridade e autenticidade.(que abordei em trabalho anterior em co-autoria com Marchi - 2005)

Estes exemplos são instrutivos por nos afastarem definitivamente de uma história linear ou determinista dos artefatos tecnológicos, que passe ao largo de sua relação com valores estéticos e culturais.

Como conseqüência, apontam primeiramente para problemas na utilização naturalizada do termo desintermediação, como se a cibercultura estivesse instaurando uma relação direta entre produtores e consumidores desencarnados, abstratos, que fazem escolhas sem constrangimentos de qualquer ordem. Ao contrário, fica claro então que as mediações podem ser de outra ordem, mas continuam a valer neste novo cenário, obrigando-nos a investigar a forma como as escolhas são feitas e discutir o peso maior ou menor das comunidades de gosto, da noção de gênero e da crítica musical, que parece estar vivendo um momento de intenso florescimento na Internet. 
Em segundo lugar, a noção de consumo participativo também merece maior problematização, uma vez que, como vimos, ela não se inaugura com a cibercultura. A customização é um desafio presente desde o início no processo de comodificação; e os embates entre as imposições de produtos fechados pela indústria e as apropriações culturais estão na origem desta história. Desta forma, cada uma das conquistas que marcam as práticas culturais de consumo consolida a noção de "atividade" do consumidor e cabe reconhecer as recentes conquistas como mais um passo - e não uma ruptura - com a história precedente.

Creio que estas ressalvas são suficientes para que eu possa concluir este texto sugerindo a necessidade de estudos pontuais que respondam às questões aqui abertas e que levem em consideração o fato de que a tecnologia propicia ao mesmo tempo um ambiente no qual pensamos e experimentamos a música, um conjunto de técnicas para produção e consumo musical e um elemento discursivo importante para avaliarmos a nossa experiência, definindo ao mesmo tempo, no processo, o que a música pode ou deve ser. (Frith; 2002)

\section{Bibliografia:}

BULL, Michael - The world according to sound. Investigating the world of walkman users. In: New Media and Society, 2001.vol.3 (2); 179-197. London, Thousand Oaks, Ca and New Delhi.

DANTAS, Danilo Fraga - MP3, a morte do álbum e o sonho de liberdade da canção? - ANAIS do V Enlepicc. Salvador, BA. Novembro de 2005

FRITH, Simon - Performing Rites. On the value of popular music.Harvard Univ Press, Cambridge, Massachussets.1996

JANOTTI Jr, Jeder Silveira - Música popular ou música pop? Trajetórias e Caminhos da Música na cultura mediática. V Enlepicc. Salvador, Ba. Nov 2005.

- À procura da batida perfeita: a importância do gênero musical para a análise da música popular massiva. Revista Eco-Pós. Rio de Janeiro.Pós-Graduação em Comunicação e Cultura. UFRJ. Vol. 6, n.2, 2003, p31-46. 
MARCHI, Leonardo de - A angústia do formato. Uma história dos formatos fonográficos.E-Compós, n.2 julho de 2004. Disponível em http//www.compos,org.br/e-compos.

SÁ, Simone Pereira de - Mediações musicais através do telefone celular. ANAIS da XVIII INTERCOM. UERJ, RJ. 2005.

SÁ, Simone Pereira de - Música eletrônica e tecnologia: reconfigurando a discotecagem. In: Lemos e Cunha (orgs) - Olhares sobre a cibercultura. pp 153-173. Porto Alegre, Ed. Sulinas, 2003

SÁ, Simone Pereira de; MARCHI, Leonardo - Não basta ser DJ. Tem que ser underground! - Revista FAMECOS, Porto Alegre, RS. v. abril de 2005.

MAGOUN, Alexander B. - The origins of the 45-rpm Record at rca Victor, 19391948. In: Braun, Hans-Joachim(org.) - Music and technology in the twentieth century. pp 148-157 Baltimore and London. John Hopkins Univ. Press, 2002

McSWAIN, Rebecca - The social reconstruction of a reverse salient in electrical guitar technology: noise, the solid body, and Jimi Hendrix. Braun, HansJoachim(org.) - Music and technology in the twentieth century. pp 186-198 Baltimore and London. John Hopkins Univ. Press, 2002

MILLARD, Andre - Tape recording and music making. IN: Braun, HansJoachim(org.) - Music and technology in the twentieth century. pp 158-167. Baltimore and London. John Hopkins Univ. Press, 2002

SHAPIRO, P. - Modulations - the book . NY, Caipirinha Productions 2000

SHUKER, Roy - Vocabulário de música pop. SP, Ed. Hedra, 1999.

STERNE, Jonathan - The audible past. Cultural origins of sound reproduction.Duke University Press, Durham end London, UK - 2003

THEBERGÉ, Paul - Any sound you can imagine: making music/Consuming technology. Hanover and London. Wesleyen Univ. Press/ Univ. Press of New England, 1997.

- Plugged in: technology and popular music. In: Frith et alli.- The Cambridge companion to Pop and Rock. pp3-25. UK, Cambridge Univ. Press, 2001 